\title{
CANCER
}

\section{The spectrum of p53 mutations in colorectal adenomas differs from that in colorectal carcinomas}

\author{
X P Hao, I M Frayling, J G Sgouros, M Q Du, T C Willcocks, I C Talbot, I P M Tomlinson
}

Gut 2002;50:834-839

See end of article for authors' affiliations

.....................

Correspondence to: I P M Tomlinson, Molecular and Population Genetics Laboratory, Cancer

Research UK, Lincoln's Inn Fields, London WC2A 3PX, UK

ian.tomlinson@cancer.org.uk

Accepted for publication 7 August 2001
Background: p53 mutations are frequently observed in colorectal carcinomas but they have also been found in colorectal adenomas, although considerably less frequently.

Aims: To explore p53 mutations in benign tumours, we have screened 70 colorectal adenomas for allelic loss at, and point mutations in, TP53 by analysis of selected microdissected cell populations.

Results: Sixteen (22.8\%) adenomas were found to have allelic loss, of which $11(15.7 \%)$ had p53 mutations. In adenomas with mild, moderate, or severe dysplasia, mutation or allelic loss occurred in $4.8 \%, 16.7 \%$, and $52.6 \%$, respectively $(p<0.001)$. Seven different mutations were found, all missense changes or inframe deletions: one (Thr150Arg) has not been found before while three (Gln 144His, Gly245Arg, and Glu285G $\mathrm{ln}$ ) have not been described previously in colorectal tumours. The other three mutations (Arg175Gly, $\Delta$ Pro 190, and Gly245Ser) have been found in colorectal carcinomas, the last commonly. Adenomas harboured a spectrum of p53 mutations which was significantly different from cancers as regards the position in the gene and a higher frequency of $G \rightarrow C / C \rightarrow G$ changes.

Conclusions: Combining our data on adenomas with data already published and in comparison with the spectrum of mutations in colorectal carcinomas, it is suggested that some p53 mutations have a weaker effect than others and are therefore more likely to be found in adenomas which have not progressed to carcinomas.
T he p53 protein plays a pivotal role in modulating cell growth, division, and apoptosis. Mutant p53 may contribute to increased cell proliferation, loss of ability to undergo apoptosis, and increasing genetic instability. ${ }^{1}$ Inactivation of $\mathrm{p} 53$ has been found in a wide variety of malignant tumours, including colorectal cancers, where it is generally believed to be critically involved in the transition from adenoma to carcinoma. ${ }^{23}$ Using immunohistochemistry (IHC), we and others have found nuclear accumulation of p53 protein in colorectal adenomas with moderate and severe dysplasia, ${ }^{4-6}$ raising the possibility that not all p53 mutations which occur in adenomas necessarily lead to rapid or inevitable progression of the tumour to malignancy. However, it is possible that accumulation of p53 in these cases may involve unusual mechanisms, without promoting malignancy.

If TP53 mutations were causal or permissive in malignant progression, it would be reasonable to expect that the spectrum of mutations in adenomas might be distinct from that in carcinomas. In this case, the TP53 mutations observed in adenomas could be explained by the fact that they confer some advantage to the cells, but are insufficient, at least on their own, to cause malignancy. If on the other hand there were no differences in the two spectra, this would be evidence that it may be some other change, highly correlated with TP53 mutation but independent of its exact nature, which in combination with (or promoted by) the TP53 mutation was the cause of progression to malignancy. Unfortunately, there are few data available to address this question. While there have been numerous reports based on IHC of p53 in adenomas, there have been few studies of actual TP53 mutations or loss of heterozygosity $(\mathrm{LOH})$, certainly in relation to the number of studies reporting TP53 mutations in colorectal carcinomas. Numerous studies have provided data on nearly 800 somatic TP53 mutations which have occurred in colorectal cancers, which contrasts with the 22 mutations that have to date been described in colorectal adenomas ${ }^{7-10}$; these have usefully been collated into databases. ${ }^{112}$ Analysis of the mutations found to occur in colorectal cancers has shown that a high proportion (approximately 50\%) occur at CpG sites, with five codons in particular $(175,245,248,273$, and 282) being especially prevalent sites of mutation. ${ }^{1313}$

To further explore the nature and significance of TP53 mutations in colorectal tumours, we have studied mutations in and LOH at TP53 in a large series of adenomas previously analysed by $\mathrm{IHC}^{6}$ and then, combined with published data, compared the findings in adenomas with those in carcinomas. Our results show that the spectrum of TP53 mutations in adenomas is different from that in carcinomas, thus leading to the conclusion that, in those cases, it is TP53 mutations per se which cause or are permissive for malignant progression.

\section{MATERIALS AND METHODS \\ Tissue samples}

Paraffin embedded blocks of 18 p53 IHC positive and 52 IHC negative colorectal adenomas were retrieved from the archives of the Academic Department of Pathology at St Mark's Hospital. These adenomas were selected according to the following standard: only patients without a personal or family history of malignancy or familial adenomatous polyposis were chosen; all polyps were completely excised by polypectomy or surgical resection; and the adenomas selected were the largest in size and severest in grade of dysplasia if multiple. All patients presented symptomatically. Histology was reviewed by two histopathologists (ICT, XPH). Serial $6 \mu \mathrm{m}$ sections were cut and lightly stained with haematoxylin and eosin for microdissection. IHC methods and results have been previously reported. ${ }^{\circ}$

\section{Microdissection and DNA preparation}

In p53 IHC positive tumours, p53 positive cells were specifically microdissected from lightly stained haematoxylin

Abbreviations: IHC, immunohistochemistry; $\mathrm{LOH}$, loss of heterozygosity; PCR, polymerase chain reaction; SSCP, single strand conformational polymorphism. 
Table 1 Details of adenomas with positive p53 immunohistochemistry $(\mathrm{IHC})$, mutations in or loss of heterozygosity $(\mathrm{LOH})$ at TP53

\begin{tabular}{|c|c|c|c|c|c|c|c|c|c|c|c|}
\hline \multirow[b]{2}{*}{ No } & \multirow[b]{2}{*}{ Sex } & \multirow[b]{2}{*}{$\begin{array}{l}\text { Size } \\
(\mathrm{cm})\end{array}$} & \multirow[b]{2}{*}{ Type } & \multirow[b]{2}{*}{ Site } & \multirow[b]{2}{*}{ Dysplasia } & \multirow[b]{2}{*}{$\mathrm{IHC}$} & \multirow[b]{2}{*}{$\mathrm{LOH}$} & \multicolumn{4}{|l|}{ Mutation } \\
\hline & & & & & & & & Location & Codon & $\begin{array}{l}\text { Nucleotide } \\
\text { change }\end{array}$ & Consequence \\
\hline ICsm0997 & $\mathrm{F}$ & 3.0 & $\mathrm{~T}$ & $\mathrm{R}$ & Moderate & + & - & - & & & \\
\hline ICsm0656 & $\mathrm{F}$ & 0.6 & $\mathrm{~T}$ & $\mathrm{R}$ & Moderate & + & - & - & & & \\
\hline ICsm0677 & $\mathrm{F}$ & 1.3 & $\mathrm{~T}$ & $\mathrm{R}$ & Moderate & + & - & - & & & \\
\hline ICsm 1231 & $M$ & 1.8 & $\mathrm{~T}$ & $S$ & Moderate & ++ & - & - & & & \\
\hline ICsm 1131 & $\mathrm{~F}$ & 2.2 & $\mathrm{~T}$ & $\mathrm{~S}$ & Severe & +++ & - & - & & & \\
\hline ICsm0522 & $M$ & 1.3 & $\mathrm{~T}$ & $\mathrm{~S}$ & Moderate & - & + & - & & & \\
\hline ICsm0741 & $\mathrm{F}$ & 0.7 & TV & $S$ & Moderate & - & + & - & & & \\
\hline ICsm0740 & $\mathrm{F}$ & 1.0 & $\mathrm{~T}$ & $\mathrm{~S}$ & Moderate & + & + & - & & & \\
\hline ICsm 1186 & $M$ & 1.5 & TV & $\mathrm{R}$ & Moderate & +++ & + & - & & & \\
\hline ICsm0951 & $M$ & 3.2 & TV & $S$ & Severe & ++ & + & - & & & \\
\hline ICsm 1300 & $\mathrm{~F}$ & 2.0 & TV & $\mathrm{R}$ & Severe & +++ & + & Exon 5 & 144 & $432 \mathrm{G} \rightarrow \mathrm{C}$ & Gln 144His \\
\hline ICsm 1169 & $M$ & 1.2 & TV & $\mathrm{S}$ & Severe & +++ & + & Exon 5 & 150 & $449 C \rightarrow G$ & Thr150Arg \\
\hline ICsm0712 & $\mathrm{F}$ & 1.7 & $\mathrm{~T}$ & $\mathrm{R}$ & Mild & + & + & Exon 5 & 175 & $523 C \rightarrow G$ & Arg 175Gly \\
\hline ICsm0976 & $M$ & 0.7 & TV & $S$ & Severe & ++ & + & Exon 6 & 192 & 572delCTC & $\Delta$ Prol90 \\
\hline ICsm0824 & $M$ & 1.5 & $\mathrm{~T}$ & $\mathrm{R}$ & Severe & + & + & Exon 7 & 245 & $733 \mathrm{G} \rightarrow \mathrm{A}$ & Gly245Ser \\
\hline ICsm0937 & $\mathrm{F}$ & 3.0 & TV & $\mathrm{S}$ & Severe & ++ & + & Exon 7 & 245 & $733 G \rightarrow C$ & Gly245Arg \\
\hline ICsm0798 & $M$ & 2.2 & TV & $\mathrm{T}$ & Moderate & + & + & Exon 7 & 245 & $733 \mathrm{G} \rightarrow \mathrm{A}$ & Gly245Ser \\
\hline ICsm 1195 & $M$ & 3.5 & TV & $\mathrm{S}$ & Severe & + & + & Exon 7 & 245 & $733 G \rightarrow A$ & Gly245Ser \\
\hline ICsm 1276 & $M$ & 0.9 & TV & $\mathrm{S}$ & Severe & + & + & Exon 7 & 245 & $733 \mathrm{G} \rightarrow \mathrm{A}$ & Gly245Ser \\
\hline & & & & & & & & Intron 8 & & IVS8+26 & Splicing? \\
\hline ICsm0589 & M & 1.2 & $\mathrm{~T}$ & $\mathrm{R}$ & Severe & - & + & Exon 8 & 285 & $853 G \rightarrow C$ & Glu285Gln \\
\hline ICsm0599 & $\mathrm{F}$ & 1.5 & $\mathrm{~T}$ & $S$ & Severe & +++ & + & Exon 8 & 285 & $853 G \rightarrow C$ & Glu285Gln \\
\hline
\end{tabular}

and eosin slides by comparison with immunostained slides. For the p53 IHC negative tumours, areas of dysplastic cells were microdissected from lightly stained haematoxylin and eosin slides. In both IHC positive and negative tumours, cells were also microdissected from histologically normal mucosa. The microdissected cell populations were digested in $100 \mu \mathrm{l}$ of $1 \times$ polymerase chain reaction (PCR) buffer without magnesium (Promega Corporation, Madison, Wisconsin, USA) containing $200 \mathrm{mg} / \mathrm{l}$ proteinase $\mathrm{K}$, for $24-48$ hours at $55^{\circ} \mathrm{C}$. Proteinase $\mathrm{K}$ was thereafter inactivated by heating to $96^{\circ} \mathrm{C}$ for 10 minutes, the cell debris pelleted by centrifugation ( 12000 $g$ for five minutes), and the supernatant used for PCR.

\section{SSCP analysis}

As the majority of TP53 mutations occur at conserved regions in exons $5,6,7,8$, and $9,{ }^{14}{ }^{15}$ these exons were amplified by PCR (exons 5, 6, and 7 separately, exons 8 and 9 in one amplicon), and mutations screened for by single strand conformational polymorphism (SSCP) analysis. ${ }^{7}$ For reliable amplification using DNA extracted from formalin fixed and wax embedded tissues, a touch down thermal cycling programme with hot start was employed, and PCR was carried out for 46 cycles of amplification. Each cycle consisted of $94^{\circ} \mathrm{C}$ for 60 seconds, an annealing step at a variable temperature for 60 seconds, and an extension step of $72^{\circ} \mathrm{C}$ for 45 seconds. For the first cycle the annealing temperature was $60^{\circ} \mathrm{C}$, reducing to $59^{\circ} \mathrm{C}$ in cycle 2 , $58^{\circ} \mathrm{C}$ in cycle $3,57^{\circ} \mathrm{C}$ in cycles $4-7,56^{\circ} \mathrm{C}$ in cycles $8-11$, and $55^{\circ} \mathrm{C}$ in cycles $12-46$. Cycling was preceded by an initial denaturation step of four minutes at $95^{\circ} \mathrm{C}$, and followed by a final elongation step of five minutes at $72^{\circ} \mathrm{C}$. PCR products were analysed by SSCP using a temperature controlled semidry electrophoresis machine (Genephor, Pharmacia, USA) utilising dedicated precast $12.5 \%$ polyacrylamide gels (GeneGel Excel 12.5) as directed by the manufacturer. PCR products were combined in pairs, either exon 5 plus exon 7, or exon 6 plus exons 8+9, and then diluted and denatured according to the instructions; the equivalent of $0.5 \mu \mathrm{l}$ of each individual PCR product was loaded per lane. Electrophoresis was performed for 60 minutes at a constant $900 \mathrm{~V}$; all samples were analysed twice, once at $5^{\circ} \mathrm{C}$ and a second time at $20^{\circ} \mathrm{C}$. The gels were silver stained according to the manufacturer's recom-
Table 2 Correlation between mutations in and loss of heterozygosity (LOH) at TP53

\begin{tabular}{ccc}
\hline & \multicolumn{2}{c}{ Mutations } \\
\cline { 2 - 3 } & + & - \\
\hline $\mathrm{LOH}$ & 11 & 5 \\
+ & 0 & 54 \\
- & & \\
\hline
\end{tabular}

$p<0.001$ by Fisher's exact test.

mendations, and viewed by two observers (XPH and IMF) to maximise the efficiency of mutation detection.

\section{DNA sequencing}

Exons in which mutations were putatively identified by SSCP were sequenced using an ABI PRISM 377 fluorescent DNA analyser (Perkin-Elmer Applied Biosystems, Foster City, California, USA). Dye deoxy terminator ready reaction mix (Perkin-Elmer Applied Biosystems) was used according to the manufacturer's instructions and using an annealing temperature of $51^{\circ} \mathrm{C}$ for five seconds. Results were analysed by three observers (XPH, IMF, and IPMT) using Sequence Navigator software (Perkin-Elmer Applied Biosystems).

\section{LOH analysis}

Allelic loss (LOH) at the TP53 locus was tested for by analysis of three flanking microsatellites: D17S1176, D17S1881, and TP5 $3^{16}{ }^{17}$ in the paired tumour and normal tissues. Oligonucleotide primers were labelled with fluorescent dyes to allow analysis using an ABI PRISM 377 fluorescent DNA analyser and GeneScan software (version 2.1.2; Perkin-Elmer Applied Biosystems), as previously described. ${ }^{18}$

\section{Statistical analysis}

The $\chi^{2}$ test or Fisher's exact test (two sided) was used to determine the statistical significance of associations between the molecular and clinical data. The $\chi^{2}$ test, on $\log _{\mathrm{e}}$ transformed data with Pearson's correction, was used to determine the log 


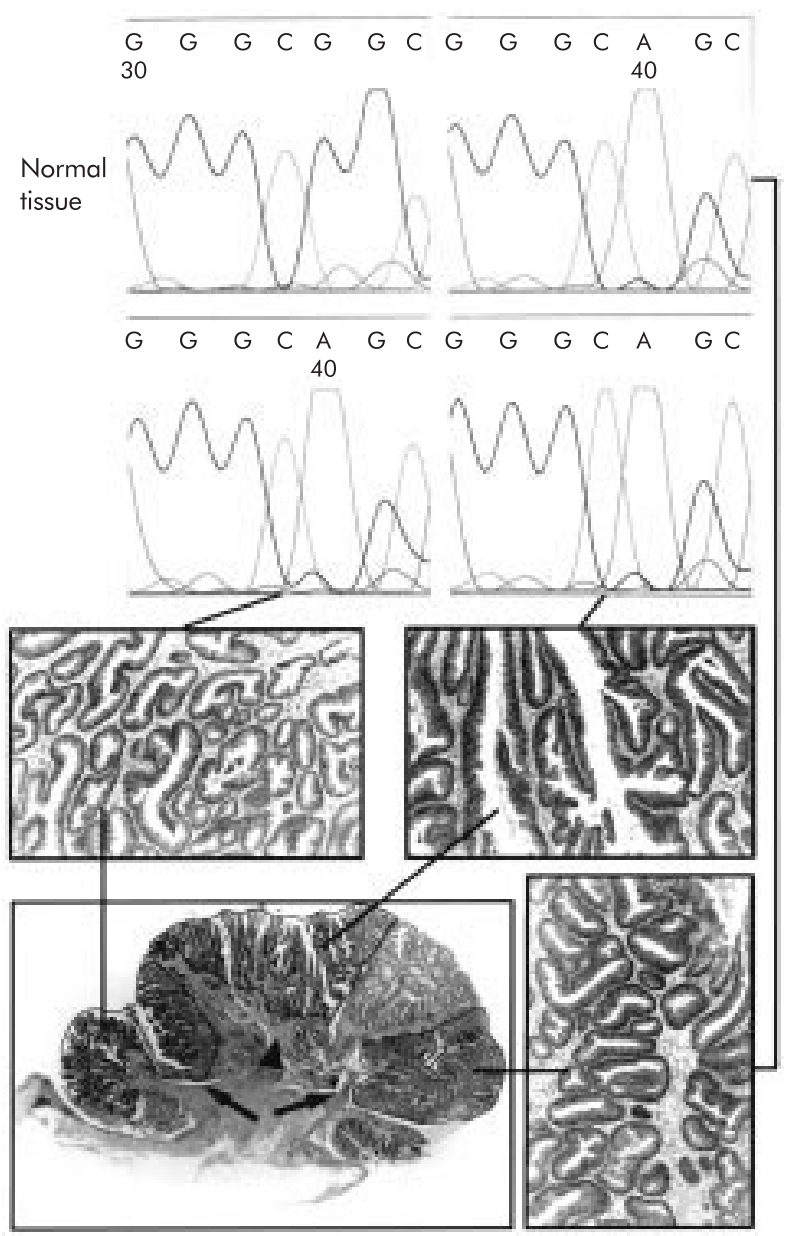

Figure 1 A section from adenoma ICsm0824 with two areas of tubular (left side, severe dysplasia; right side, moderate dysplasia; arrows) and one area of villous (arrowhead) architecture with severe dysplasia. The attached sequencing electropherograms, derived from material microdissected from each area, show that the same TP53 exon 7 mutation (GGC $\rightarrow$ AGC; Gly245Ser) is present in all three areas.

likelihood ratio for the comparison of mutational position in the different tumour types.

\section{Previously described TP53 mutations}

For comparison with previously described somatic TP53 mutations, advantage was taken of the IARC database of p53 gene mutations in human tumours and cell lines (http:// www.iarc.fr/p53/homepage.htm). Version (Rl) was imported into Microsoft Access for Windows 95 (v7.00). Adenoma data

Table 3 Mutations in or loss of heterozygosity $(\mathrm{LOH})$ at TP53 by histological grade and size

\begin{tabular}{lrrl}
\hline & \multicolumn{2}{c}{ Mutation or LOH } & p Value \\
\cline { 2 - 3 } & + & - & \\
\hline Dysplasia & 1 & 20 & \\
$\quad$ Mild & 5 & 25 & $<0.0008$ \\
$\quad$ Moderate & 10 & 9 & \\
$\quad$ Severe & 4 & 21 & $>0.35$ \\
Size & 12 & 33 & \\
$<1 \mathrm{~cm}$ & & & \\
$>1 \mathrm{~cm}$ & 10 & & \\
\hline
\end{tabular}

Fisher's exact test, mild plus moderate versus severe, $<1 \mathrm{~cm}$ versus $>1$ $\mathrm{cm}$.
Table 4 Correlation between p53 immunohistochemistry $(\mathrm{IHC})$ and mutations in or loss of heterozygosity (LOH) at TP53

\begin{tabular}{rrr}
\hline & Mutation or LOH \\
\cline { 2 - 3 } & + & - \\
\hline $\mathrm{HC}$ & 13 & 5 \\
+ & 3 & 49 \\
- & & \\
\hline
\end{tabular}

$\mathrm{p}<0.001$, Fisher's exact test.

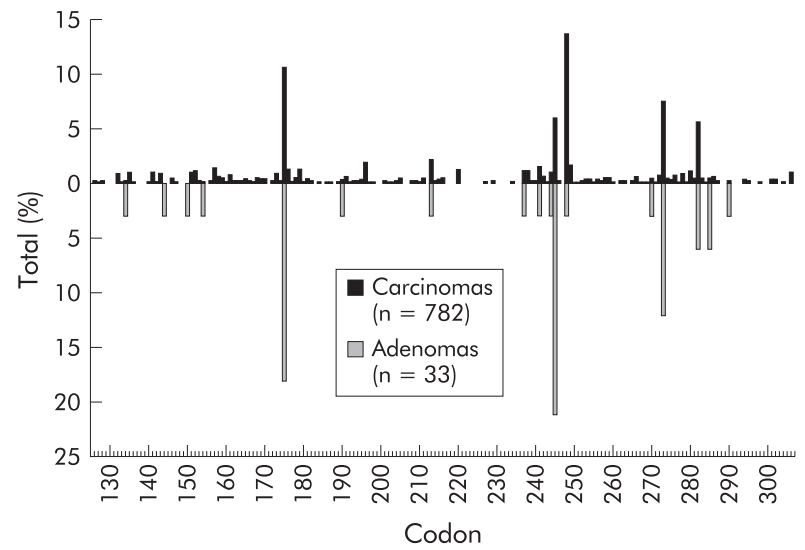

Figure 2 The frequency of somatic TP53 mutations found in colorectal adenomas $(n=33)$ and carcinomas $(n=782)$ between codons 125 and 306 (exons 5-9), given as a percentage and plotted by codon (data from this study, and Hainaut and colleagues' and Beroud and Soussi $\left.{ }^{2}\right)$. Whereas the commonest site of mutation in carcinomas (codon 248) is underrepresented in adenomas, a mutation at codon 245, the fourth commonest site in carcinomas, is the commonest site in adenomas. Mutations at codons 144 and 150 have only been found in adenomas.

were also gleaned from the p53 Data Base (http:// perso.curie.fr/Thierry.Soussi/), care being taken to eliminate entries duplicated on both databases. For determination of TP53 mutation frequencies in colorectal carcinomas, data were excluded from tumours other than adenomas or carcinomas (for example, carcinoids), cell lines, familial cases, silent mutations, and mutations in exons $1,2,3,4,10$, or 11 .

\section{RESULTS}

The results of the p53 mutation screen and $\mathrm{LOH}$ analysis are summarised in table 1 .

Eleven adenomas had mutations which in all cases were found together with $\mathrm{LOH}$; thus mutation and $\mathrm{LOH}$ were

Table 5 Comparison of the TP53 mutational spectra of colorectal adenomas and carcinomas

\begin{tabular}{lcc}
\hline Codons & Carcinomas & Adenomas \\
\hline $126-174,176-244,246-247$, & 439 & 13 \\
$249-272,274-281$, and 283-306 & & \\
175 & 83 & 6 \\
245 & 47 & 7 \\
248 & 108 & 1 \\
273 & 61 & 4 \\
282 & 44 & 2 \\
All & 782 & 33 \\
\hline
\end{tabular}

$\chi^{2}=14.98$ on $\log _{e}$ transformed data; log likelihood ratio $=0.01$ Data combined from this study and public databases. ${ }^{11} 12$ 


\begin{tabular}{|c|c|c|c|c|c|c|}
\hline \multirow[b]{2}{*}{ Normal } & \multirow[b]{2}{*}{ Codon } & \multirow[b]{2}{*}{ Mutant } & \multicolumn{2}{|c|}{ Adenomas* } & \multicolumn{2}{|c|}{ Carcinomas $\dagger$} \\
\hline & & & No & $\%$ & No & $\%$ \\
\hline \multirow[t]{2}{*}{ Phe } & 134 & Leu & & & 1 & $0.1 \ddagger$ \\
\hline & & Ser & 1 & 3.0 & 1 & 0.1 \\
\hline Gln & 144 & His§ & 1 & 3.0 & & \\
\hline Thr & 150 & Arg & 1 & 3.0 & & \\
\hline Gly & 154 & Asp & 1 & 3.0 & 1 & 0.1 \\
\hline \multirow[t]{6}{*}{ Arg } & 175 & Cys & & & 2 & 0.3 \\
\hline & & Gly & 1 & 3.0 & 1 & 0.1 \\
\hline & & His & 6 & 18.2 & 74 & 9.5 \\
\hline & & Leu & & & 4 & 0.5 \\
\hline & & Pro & & & 1 & 0.1 \\
\hline & & Ser & & & 1 & 0.1 \\
\hline \multirow[t]{3}{*}{ Arg } & 213 & Gln & & & 1 & 0.1 \\
\hline & & Leu & & & 1 & 0.1 \\
\hline & & Stop & 1 & 3.0 & 15 & 1.9 \\
\hline \multirow[t]{4}{*}{ Met } & 237 & Frameshift & & & 1 & 0.1 \\
\hline & & lle & & & 6 & 0.8 \\
\hline & & Leu & 1 & 3.0 & 1 & 0.1 \\
\hline & & Lys & & & 1 & 0.1 \\
\hline \multirow[t]{3}{*}{ Ser } & 241 & Cys & 1 & 3.0 & 2 & 0.3 \\
\hline & & Frameshift & & & 2 & 0.3 \\
\hline & & Phe & & & 8 & 1.0 \\
\hline \multirow[t]{4}{*}{ Gly } & 244 & Asp & & & 2 & 0.3 \\
\hline & & Cys & & & 3 & 0.4 \\
\hline & & Ser & & & 2 & 0.3 \\
\hline & & Val & 1 & 3.0 & 1 & 0.1 \\
\hline \multirow[t]{6}{*}{ Gly } & 245 & $\operatorname{Arg}$ & 1 & 3.0 & & \\
\hline & & Asp & 1 & 3.0 & 13 & 1.7 \\
\hline & & Cys & & & 4 & 0.5 \\
\hline & & His & & & 1 & 0.1 \\
\hline & & Ser & 5 & 15.2 & 25 & 3.2 \\
\hline & & Val & & & 4 & 0.5 \\
\hline \multirow[t]{3}{*}{ Arg } & 248 & Gln & & & 51 & 6.5 \\
\hline & & Leu & & & 2 & 0.3 \\
\hline & & Trp & 1 & 3.0 & 54 & 6.9 \\
\hline \multirow[t]{2}{*}{ Phe } & 270 & Cys & & & 1 & 0.1 \\
\hline & & Ile & 1 & 3.0 & 3 & 0.4 \\
\hline \multirow[t]{2}{*}{ Arg } & 273 & Cys & 1 & 3.0 & 32 & 4.1 \\
\hline & & $\mathrm{His}$ & 3 & 9.1 & 27 & 3.5 \\
\hline \multirow[t]{3}{*}{ Arg } & 282 & Gln & & & 3 & 0.4 \\
\hline & & Leu & & & 1 & 0.1 \\
\hline & & Trp & 2 & 6.1 & 40 & 5.1 \\
\hline \multirow[t]{4}{*}{ Glu } & 285 & Asp & & & 1 & 0.1 \\
\hline & & Gln & 2 & 6.1 & & \\
\hline & & Lys & & & 2 & 0.3 \\
\hline & & Stop & & & 1 & 0.1 \\
\hline \multirow{2}{*}{ Arg } & 290 & Frameshift & 1 & 3.0 & 1 & 0.1 \\
\hline & & His & & & 1 & 0.1 \\
\hline
\end{tabular}

*This study plus data from public databases. ${ }^{11} 12$

†As in the public databases. ${ }^{11} 12$

$\ddagger$ Percentage of the 782 colorectal carcinomas described in the public databases. ${ }^{11} 12$

$\S \mathrm{Gln} 144$ Stop mutation has been described in a herititary non-polyposis colorectal cancer. ${ }^{24}$

strongly correlated $(\mathrm{p}<0.001$, Fisher's exact test) (table 2$)$. Ten of the mutations were missense changes and one was a $3 \mathrm{bp}$ deletion having the effect of removing one of the two proline residues at codons 190 and 191 ( $\Delta$ Prol90; table 1 ). Adenoma ICsml169 was found to have a missense point mutation not previously described in any form of neoplasm $(449 \mathrm{G} \rightarrow \mathrm{C}$; Thr150Arg). Another adenoma (ICsm1276) with a missense mutation in exon 7 (Gly245Ser) and LOH had a second sequence variant of uncertain significance, an insertion of AT in place of a G in intron 8 (IVS8+26delGinsAT). Interestingly, in one adenoma (ICsm0824) it was possible to show that both the pattern of $\mathrm{LOH}$ and the same mutation (Gly245Ser) were present in three histologically distinct areas, one tubular area with moderate dysplasia, and one tubular and one villous area with severe dysplasia (fig l).

Given the strong correlation between mutations and $\mathrm{LOH}$ (table 2), tumours with either of these events were combined in a single group for further statistical analysis. Severely dysplastic adenomas displayed a significantly increased frequency of mutation or LOH compared with those with mild and moderate dysplasia $\left(\mathrm{p}<0.001, \chi^{2}\right.$ test) (table 3$)$ but there was no correlation with size $\left(\mathrm{p}>0.25 ; \chi^{2}\right.$ test) or histological type (tubular $v$ tubulovillous plus villous) (data not shown). Positive IHC was correlated with mutation or $\mathrm{LOH}$ (table 4) but the relationship was not absolute: three IHC negative adenomas and three of eight IHC positive but mutation negative adenomas were found to have $\mathrm{LOH}$.

Data available from other studies on TP53 mutations in adenomas $(n=22)$ were combined with our data $(n=11)$ and the sites of the mutations were plotted on a multiple alignment of p53 sequences from human plus seven other mammalian species (details not shown). All mutations observed in adenomas occurred at residues either absolutely or highly conserved. An initial comparison (fig 2) was then made of the combined adenoma data with those available ${ }^{11} 12$ on p53 mutations in colorectal carcinomas $(n=782)$. From this 
Table 7 Mutation spectrum in terms of base change in adenomas and carcinomas

\begin{tabular}{|c|c|c|c|c|c|}
\hline & $\begin{array}{l}\text { This study } \\
\text { (adenomas) }\end{array}$ & $\begin{array}{l}\text { Previous studies } \\
\text { (adenomas) }\end{array}$ & All adenomas & Carcinomas & Total \\
\hline INS/DEL & 1 & 1 & 2 & 92 & 94 \\
\hline$A \rightarrow C$ & & 1 & 1 & 10 & 11 \\
\hline$A \rightarrow G$ & & & 0 & 59 & 59 \\
\hline$A \rightarrow T$ & & & 0 & 18 & 18 \\
\hline$C \rightarrow A$ & & & 0 & 21 & 21 \\
\hline$C \rightarrow T$ & & 6 & 6 & 291 & 297 \\
\hline $\mathrm{G} \rightarrow \mathrm{A}$ & 4 & 12 & 16 & 431 & 447 \\
\hline$G \rightarrow T$ & & 1 & 1 & 85 & 86 \\
\hline $\mathrm{T} \rightarrow \mathrm{A}$ & & 1 & 1 & 25 & 26 \\
\hline $\mathrm{T} \rightarrow \mathrm{C}$ & & 1 & 1 & 35 & 36 \\
\hline $\mathrm{T} \rightarrow \mathrm{G}$ & & & 0 & 17 & 17 \\
\hline$C \rightarrow G$ & 2 & 2 & 4 & 17 & 21 \\
\hline $\mathrm{G} \rightarrow \mathrm{C}$ & 4 & & 4 & 34 & 38 \\
\hline Total & 11 & 25 & 36 & 1135 & 1171 \\
\hline
\end{tabular}

Data combined from this study and public databases. ${ }^{11} 12$ Coding strand change is shown.

it appeared that although the two mutational spectra were broadly similar, there were differences in detail: firstly, the commonest site of mutation in carcinomas $(13.8 \%)$ at codon 248 was relatively underrepresented in adenomas (3.0\%), where instead the commonest site was codon $245(21.2 \% \mathrm{v}$ $6.0 \%$ in carcinomas); and secondly, in adenomas there were four mutations at the $5^{\prime}$ end of the gene (Phel34Ser, Gln144His, Thrl50Arg, and Glyl54Asp) which had been described rarely, if at all, in colorectal carcinomas. Statistical analysis of the frequency of mutations observed between codons 126 and 306 (exons 5-9) at the five commonest sites in carcinomas, plus all other codons between 126 and 306 combined, gave a log likelihood ratio of 0.01, supporting the hypothesis that the mutational spectra differed in distribution (table 5). A third point of contrast became evident when the nature of the mutations occurring at the same codon in both tumour types was considered (table 6). From this table it can be seen that there were frequent differences between the two tumour types; for example, while codon 245 was the fourth most common site in carcinomas, it was the most common site in adenomas because of both overrepresentation of the Gly245Ser mutant and a mutation never seen in carcinomas (Gly245Arg) which was observed in one adenoma. Similarly, codon 285 was an uncommon site for mutations in carcinomas $(0.5 \%)$ but in adenomas it was a frequent site $(6.1 \%)$ and, moreover, all because of a mutation (Glu285Gln) only seen in adenomas. Finally, consideration of the frequency of nucleotide changes in adenomas and carcinomas (table 7) showed $\mathrm{G} \rightarrow \mathrm{C} / \mathrm{C} \rightarrow \mathrm{G}$ changes to be significantly more common in adenomas than in cancers (Fisher's exact test, $\mathrm{p}<0.00026$ ). The reasons for this excess of $\mathrm{G} \rightarrow \mathrm{C} / \mathrm{C} \rightarrow \mathrm{G}$ changes are unclear, with no obvious explanation in terms of extrinsic mutagens or intrinsic hypermutability.

\section{DISCUSSION}

We have found in sporadic colorectal adenomas that mutations in, and LOH at, TP53 are significantly correlated both with each other and with severe dysplasia. To analyse the mutation and $\mathrm{LOH}$ profile in colorectal adenomas, we took care that DNA samples were specifically extracted from microdissected p53 IHC positive cells or from areas of defined morphology in negatively staining cases, thereby minimising possible contamination by non-neoplastic tissues, or mixing of different grades of dysplasia. We found that 52.6\% (10/19) (table 3 ) of severely dysplastic adenomas exhibited mutations and $\mathrm{LOH}$, which is in line with a previously reported frequency of LOH of $45 \%$ in highly dysplastic adenomas. ${ }^{19}$ It also closely matches a frequency of $50-55 \%$ which has been reported in carcinomas. ${ }^{3}$ Together these results show that TP53 mutations frequently occur at the severely dysplastic stage in sporadic adenomas, before the transition to carcinoma.

We found one adenoma with moderate and severe dysplasia in two discrete tubular areas and one area of villous histology with severe dysplasia, all showing the same point mutation and pattern of $\mathrm{LOH}$. This clonal homogeneity implies that the TP53 mutation was a relatively early event which preceded the divergence in architecture and grade of dysplasia in this adenoma, and suggests that this histological feature is unrelated to TP53 status, at least in this tumour.

Two adenomas with mutations and one with $\mathrm{LOH}$ were negatively immunostained for p53, despite our use of a sensitive method for antigen retrieval and the use of the antibody Do-7, which can recognise both wild and mutant p53. Similar findings have been previously reported..$^{9}$ One explanation could be that the half life of mutant p53 may not always be increased enough to permit detectable levels of protein. ${ }^{2021}$ Alternatively, p53 protein expression may be transcriptionally modulated by other proteins such as mdm-2. Our mutation/ LOH positive but p53 IHC negative tumours may harbour mutations in mdm-2 or related genes. The extent to which mdm-2 influences p53 expression in colorectal neoplasms warrants further investigation. Four adenomas showing positive immunostaining were found neither to harbour mutations nor to show $\mathrm{LOH}$. The explanation for this probably lies in the fact that no single mutation detection technique is $100 \%$ efficient, we sought mutations only in exons 5-9, and we did not assess transcriptional silencing of p53. These factors may also explain why we detected LOH at a higher frequency than p53 point mutations (although we cannot exclude the possibility that LOH occasionally targeted a different locus on $17 p)$.

Only three of the seven different point mutations which we found in adenomas (table 5) have been described among the many hundred TP53 mutations seen in colorectal cancers, and only Gly245Ser commonly so. ${ }^{112}$ The remaining four mutations have not been found in colorectal carcinomas, and one (Thr150Arg) has never been seen before in any form of neoplasia. Gln144His, Gly245Arg, and Glu285Gln, although found in other types of malignancy, have not been described in colorectal carcinomas or adenomas. In addition, Gly245Ser and Glu285Gln were each found independently in more than one adenoma, suggesting that they are not rare events. The 3 bp deletion having the effect of an inframe deletion of one amino acid ( $\Delta$ Pro 190$)$ has been previously described in three colorectal cancers, an acute lymphatic leukaemia, and an astrocytic glioma. Arg 175Gly has been found in one colorectal carcinoma but by far the commonest observed mutation in 
colorectal cancers at this codon is Arg 175His (table 5). In no case did we detect "three hits" at p53 in any colorectal adenoma, although this phenomenon has been reported in some carcinomas. ${ }^{22}$

Our analysis of the mutational spectra in colorectal adenomas and carcinomas shows that they differ in both site (codon; table 5) and probably also type (amino acid substitution, table 6 and base change, table 7). While it is possible that some bias has been introduced by differences between studies in the mutation detection methods used, SSCP analysis has been frequently used to find TP53 mutations. Similarly, we confined our studies to the most frequently studied exons ${ }^{5-9}$ and only took published data from the same region; thus any bias caused by differences in methods between studies is likely to be small.

Taken together, the data suggest that the TP53 mutation spectra in colorectal adenomas and carcinomas are broadly similar, supporting the notion that most TP53 mutations are directly or indirectly involved in the transition from an adenoma to a carcinoma. That the TP53 mutations seen in adenomas are at amino acid residues either absolutely or highly conserved between mammalian species, and that they are accompanied by allelic loss, provides evidence that they are of functional significance rather than some chance phenomenon. However, we have found notable and specific differences in mutation spectra between adenomas and carcinomas, implying that some TP53 mutations, although conferring a selectable growth advantage, may be either incapable of effecting malignant transformation (at least on their own), or may even be incompatible with it. This hypothesis is supported by recent data from Greenblatt and colleague ${ }^{22}$ which suggest that codon 144 mutations affect buried amino acid residues on the non-DNA binding side of the p53 molecule and may have relatively weak effects. Codon 150 mutations moreover have little or no effect in in vitro assays of $\mathrm{p} 53$ function, ${ }^{23}$ suggesting that they too are only weakly selected. An alternative, but perhaps less likely, explanation for our data is that the different mutation spectra might reflect the effectiveness of different extrinsic carcinogens or intrinsic genomic instability in promoting carcinogenesis. Although we recognise that confirmatory data are needed, we suggest, in summary, that some p53 mutations are better than others at promoting (or permitting) progression from colorectal adenoma to carcinoma.

\section{ACKNOWLEDGEMENTS}

We would like to thank Stewart Payne (Kennedy-Galton Centre for Human Genetics, Northwick Park Hospital) for the generous loan of a Genephor machine, Kevin Pack and Victoria Johnson (ICRF Colorectal Unit) for technical assistance, and Graham Clark and Andrew Davies (ICRF Equipment Park) for assistance with the microsatellite and sequencing analysis. This work was supported by the Imperial Cancer Research Fund.

\section{Authors' affiliations}

X P Hao*, Academic Department of Pathology and Colorectal Cancer Unit, Imperial Cancer Research Fund, St Mark's Hospital, Harrow HAI 3UJ, UK

I M Fraylingt, Colorectal Cancer Unit, Imperial Cancer Research Fund, St Mark's Hospital, Harrow HAl 3UJ, UK

J G Sgouros, Computational Genome Analysis Laboratory, Imperial Cancer Research Fund, Lincoln's Inn Fields, London WC2A 3PX, UK M Q Du, Department of Histopathology, University College of London, Gower St, London WC1E 6BT, UK

T C Willcocks, School of Biosciences, University of Westminster, 115
New Cavendish Street, London WIM 8JS, UK

I C Talbot, Academic Department of Pathology and Colorectal Cancer Unit, Cancer Research UK, St Mark's Hospital, Harrow HAl 3UJ, UK

I P M Tomlinson, Molecular and Population Genetics Laboratory, Cancer Research UK, Lincoln's Inn Fields, London WC2A 3PX, UK

Present addresses: *Institute of Pathology, Case Western Reserve University School of Medicine, University Hospital of Cleveland, 2085 Adelbert Road, Cleveland, OH 44106, USA; †Cambridge University

Department of Medical Genetics, Molecular Genetics Laboratory, Box 158, Addenbrooke's NHS Trust, Cambridge CB2 2QQ, UK

\section{REFERENCES}

1 Levine AJ. p53, the cellular gatekeeper for growth and division. Cell 1997:88:323-31.

2 Fearon ER, Vogelstein B. A genetic model for colorectal tumorigenesis. Cell 1990;61:759-67

3 Greenblatt MS, Bennett WP, Hollstein M, et al. Mutations in the p53 tumor suppressor gene: clues to cancer etiology and molecular pathogenesis. Cancer Res 1994:54:4855-78.

4 Pignatelli M, Stamp GW, Kafiri G, et al. Over-expression of p53 nuclear oncoprotein in colorectal adenomas. Int J Cancer 1992;50:683-8.

5 Sinicrope FA, Ruan SB, Cleary KR, et al. bcl-2 and p53 oncoprotein expression during colorectal tumorigenesis. Cancer Res 1995:55:237-41.

6 Hao XP, llyas M, Talbot IC. Expression of Bcl-2 and p53 in the colorecta adenoma-carcinoma sequence. Pathobiology 1997;65:140-5.

7 Kikuchi-Yanoshita R, Konishi M, Ito S, et al. Genetic changes of both p53 alleles associated with the conversion from colorectal adenoma to early carcinoma in familial adenomatous polyposis and non-familial adenomatous polyposis patients. Cancer Res 1992;52:3965-71.

8 De Benedetti L, Varesco L, Pellegata NS, et al. Genetic events in sporadic colorectal adenomas: K-ras and p53 heterozygous mutations are not sufficient for malignant progression. Anticancer Res 1993; 13:667-70.

9 Ohue $\mathbf{M}$, Tomita N, Monden T, et al. A frequent alteration of p53 gene in carcinoma in adenoma of colon. Cancer Res 1994;54:4798-804.

10 Yamaguchi K, Sugano K, Fukayama N, et al. Polymerase chain reaction-based approaches for detection of allelic loss in the p53 tumor suppressor gene in colon neoplasms. Am J Gastroentero 1997;92:307-12.

11 Hainaut P, Hernandez T, Robinson A, et al. IARC Database of p53 gene mutations in human tumors and cell lines: updated compilation, revised formats and new visualisation tools. Nucleic Acids Res 1998;26:205-13.

12 Beroud C, Soussi T. p53 gene mutation: software and database. Nucleic Acids Res 1998;26:200-4

13 Harris CC. p53 tumor suppressor gene: from the basic research laboratory to the clinic-an abridged historical perspective. Carcinogenesis 1996;17:1187-98

14 Hollstein M, Sidransky D, Vogelstein B, et al. p53 mutations in human cancers. Science 1991;253:49-53.

15 Levine AJ, Perry ME, Chang A, et al. The 1993 Walter Hubert Lecture: the role of the $\mathrm{p} 53$ tumour-suppressor gene in tumorigenesis. $\mathrm{Br} J$ Cancer 1994;69:409-16.

16 Jones MH, Nakamura Y. Detection of loss of heterozygosity at the human TP53 locus using a dinucleotide repeat polymorphism. Genes Chromosomes Cancer 1992:5:89-90.

17 Cohen D, Chumakov I, Weissenbach J. A first-generation physical map of the human genome. Nature 1993;366:698-701.

18 Frayling IM, Bodmer WF, Tomlinson IP. Allele loss in colorectal cancer at the Cowden disease/juvenile polyposis locus on 10q. Cancer Genet Cytogenet 1997; 97:64-9.

19 Boland CR, Sato J, Appelman HD, et al. Microallelotyping defines the sequence and tempo of allelic losses at tumour suppressor gene loci during colorectal cancer progression. Nat Med 1995;1:902-9.

20 Wynford-Thomas D. P53 in tumour pathology: can we trust immunocytochemistry? J Pathol 1992;166:329-30.

21 Dix B, Robbins P, Carrello S, et al. Comparison of p53 gene mutation and protein overexpression in colorectal carcinomas. $\mathrm{Br} J$ Cancer 1994;70:585-90

22 Greenblatt MS, Chappuis PO, Bond JP et al. TP53 mutations in breast cancer associated with BRCA1 or BRCA2 germ-line mutations: distinctive spectrum and structural distribution. Cancer Res 2001;61:4092-7.

23 Walker DR, Bond JP, Tarone RE, et al. Evolutionary conservation and somatic mutation hotspot maps of p53: correlation with p53 protein structural and functional features. Oncogene 1999;18:211-18.

24 Losi L, Ponz de Leon M, Jiricny J, et al. K-ras and p53 mutations in hereditary non-polyposis colorectal cancers. Int J Cancer 1997;74:94-6. 